\title{
Phytoconstituents, extraction and analysis of chemical compounds of Crataegus pontica K.Koch fruit using HS-SPME and GC-MS methods
}

\author{
Nasrin Bazgir ${ }^{1}$, Abbas Ghaysouri ${ }^{1^{*}}$, Pegah Shakib ${ }^{2}$ \& Masoumeh Tahmasebi ${ }^{3,4}$ \\ ${ }^{1}$ Department of Internal Medicine, School of Medicine, Ilam University of Medical Sciences, Ilam, Iran \\ ${ }^{2}$ Razi Herbal Medicines Research Center, Lorestan University of Medical Sciences, Khorramabad, Iran \\ ${ }^{3}$ Department of Emergency Medicine, School of Medicine, Ilam University of Medical Sciences, Ilam, Iran \\ ${ }^{4}$ Biotechnology and Medical Plants Research Center, Ilam University of Medical Sciences, Ilam, Iran \\ *Email: gheysouri.abas@ymail.com
}

\section{ARTICLE HISTORY}

Received: 07 July 2020

Accepted: 22 September 2020

Published: 01 October 2020

\section{KEYWORDS}

Crataegus pontica; Fruit; HS-SPME; GC-MS; Chemical compounds
ABSTRACT

Essential oils were extracted by HS-SPME method from the fruit of the Crataegus pontica K.Koch collected from the southern regions of llam province. Then, to identify chemical compounds, the essential oil was injected into a chromatograph gas device connected to a mass spectrometer (GC-MC). Of the 50 compounds identified in this essential oil, beta-Thujene (17.21\%), alpha-pinene (15.40\%), 2Hexenal (12.42\%), trans-Caryophyllene (8.76\%), beta-Myrcene (7.89\%), 1-Pentadecene (5.89\%), Sabinene (4.33\%) and trans-beta-Farnesene accounted for \%3.50 of the major fruit essential oil compounds of $C$. pontica.

\section{Introduction}

Hawthorn (Crataegus pontica K. Koch), belonging to the Rosaceae family, is one of the edible fruits. It is a 6-10 meters tall tree with young, hairy, thorny branches, leaves 3 to $7 \mathrm{~cm}$ long and 2.5 to $6.5 \mathrm{~cm}$ wide and bayonet, with short, fluffy petioles (1). This plant is distributed in Lorestan, Ilam, Chalous, Chaharmahal and Bakhtiari, Kermanshah, Islamabad Gharb, Sarpole Zahab, Ardabil, Qom, Hamedan, Khuzestan and Urmia in Iran. The ripe, yellow fruits of the common hawthorn tree are eaten raw in the fall semester and have healing effects (1). The use of hawthorn in the treatment of diseases and medical disorders dates back to ancient times (1). It has been used as one of the useful medicinal plants for the treatment of cardiovascular diseases (2-4). In traditional Iranian medicine, hawthorn is used to treat neurological disorders such as anxiety, insomnia, dizziness, tingling in the ears (tinnitus) and heart failure, angina and aortic oedema, anti-anxiety, improved digestion, antihypertension, skin beauty, analgesic, treatment of constipation and diarrhoea (5). Phytochemical studies show that flavonoids and anthocyanins are the most important chemical compounds in hawthorn fruit (6, 7). Quercetin, isocoercistin, vitoxin, hyperoside and chlorogenic acid are other compounds of hawthorn (8, 9). In this phytochemical study, it was tried to extract essential oils and volatile oils from the dried powder of hawthorn fruit by headspace-solid phase microextraction (HS-SPME), and then its chemical compounds were analyzed using GC-MS technique.

\section{Materials and Methods}

\section{Method of preparing the plant material}

In September of 2019, the hawthorn fruit was collected from the mountainous areas of Maymeh section of Dehloran city in the south of Ilam province (western Iran) [32 $41^{\prime} 28^{\prime \prime}$ North, $47^{\circ} 15^{\prime}$ 58" East]. The plant was identified and confirmed using the flora of Ilam province (Fig. 1). The species was determined at the Biotechnology and Medicinal Plants Research Center, Ilam University of Medical Sciences, Ilam, Iran. The collected fruit was cleaned and dried in the laboratory at room temperature. The dried fruit was powdered by a mixer. The plant essence was extracted by HS-SPME method and the chemical composition of the fruit was identified by GC-MS method. The details of hawthorn are specified in Table 1.

(C) Bazgir et al (2020). This is an open-access article distributed under the terms of the Creative Commons Attribution License, which permits unrestricted use, distribution and reproduction in any medium, provided the original author and source are credited (https://creativecommons.org/licenses/by/4.0/)

To cite this article: Bazgir N, Ghaysouri A, Shakib P, Tahmasebi M. Phytoconstituents, extraction and analysis of chemical compounds of Crataegus pontica K.Koch fruit using HS-SPME and GC-MS methods. Plant Science Today. 2020;7(4):617-622. https://doi.org/10.14719/pst.2020.7.4.860 


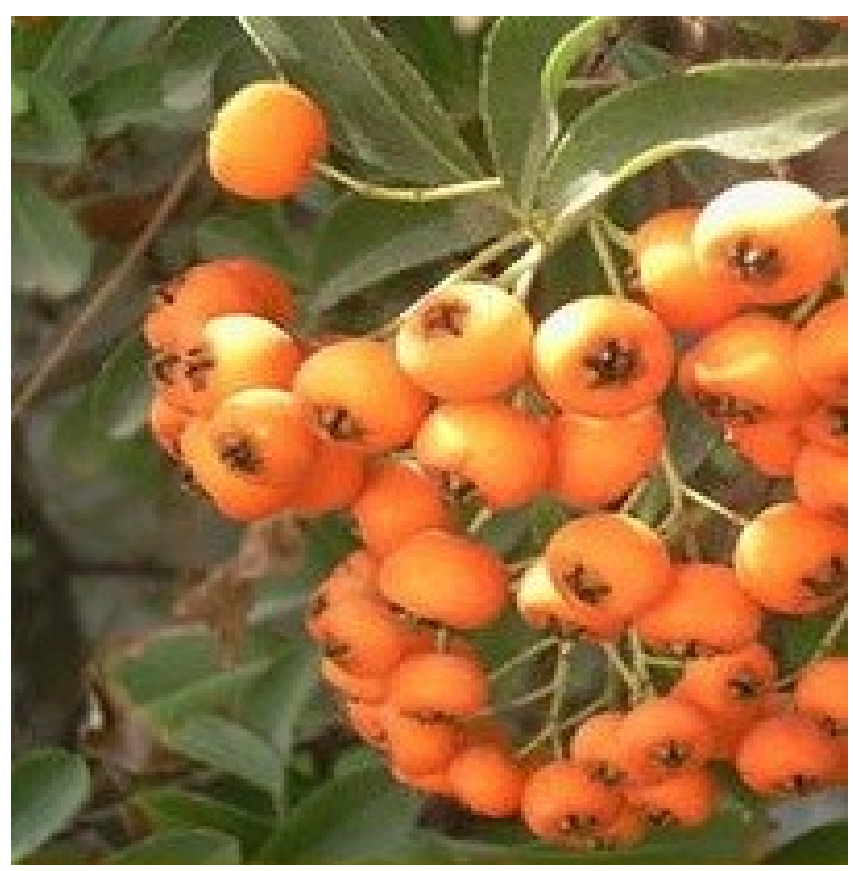

Fig. 1. Crataegus pontica K. Koch fruit

\section{Extraction of essential compounds by HS-SPME method}

In this experiment, the essential oil of hawthorn fruit was extracted by HS-SPME technique. In the HS-SPME technique, 2 gms of dry powder is placed in the vial, and the vial temperature rises between $60-70{ }^{\circ} \mathrm{C}$. These temperature conditions are optimal so that the vapours of the substances in the essential oil are saturated in the space above the solid surface. The SPME syringe is then placed in the upper part of the container with the lid closed, and the material in the plant vapour is absorbed by the silica phase in the needle of the device $(10,11)$.
Extraction mode: (HSSPME); SMPE fibers: PDMS 100 micrometer thickness (SUPELCO); Sample weight: 0.5 g; Extraction temperature: $60^{\circ} \mathrm{C}$; Extraction time: 20 minutes; Ultrasound time: 10 minutes (Eurovond ultrasound) Tools, Italy and time discharge in the port GC-MS injector: 3 minutes (11).

\section{Results}

Crataegus pontica fruit extract was extracted by HSSPME method, and GC-MS method was analyzed. The results of the phytochemical analysis of hawthorn fruit essential oil are given in Table 2. Essential oil of Crataegus pontica fruit contain 50 chemical compounds. Accordingly, the major fruit essential oil compounds of this plant are a-bisabolol oxide A (19.07\%), a-Pinene (15.50\%), $\beta$-Bisabolene (12.56\%), spathulenol (9.23\%), $\beta$-Farnesene (8.95\%), $\alpha$-Bisabolol $(4.72 \%)$, caryophyllene oxide $(4.46 \%)$, trans-Farnesole (3.75\%) and dl-limonene (3.47\%). Other ingredients of hawthorn essential oil are listed in Table 2.

\section{Discussion}

Production, exploitation and processing of herbal medicinal products are increasing due to the long history in traditional medicine and herbal medicine, as well as to avoid or reduce the adverse effects of the increasing use of chemical drugs. In particular, identifying the compounds of medicinal plants to produce natural medicines is more necessary. Recognition of medicinal plants and their medicinal or hygienic and industrial use in their compounds have long been considered by many researchers. So far, no study has been done on the chemical composition of Crataegus pontica fruit by HS-SPME and GC-MS method, which can be a new scientific document for reporting

Table 1. Details of $C$. pontica

\begin{tabular}{cccccc}
\hline Scientific name & $\begin{array}{c}\text { Common } \\
\text { name }\end{array}$ & Persian name & Plant family & Collection area & Geographical coordinates \\
\hline Crataegus pontica K.Koch & Hawthorn & Zalzalak & Rosaceae & $\begin{array}{c}\text { Dehloran, Ilam } \\
\text { province }\end{array}$ & $\begin{array}{c}32^{\circ} 41^{\prime} 28^{\prime \prime} \text { North, } 47^{\circ} 15^{\prime} 58^{\prime \prime} \\
\text { East }\end{array}$ \\
\hline
\end{tabular}

\section{Identification of essential plant compounds by GC-MS method}

After extracting the essential oil, silica fibre from the volatile compounds, the fibre is placed directly in the inlet of the GC-MS device, and due to the temperature of the input part, the materials in the fibre are absorbed and enter the GC-MS device (10). About 2 (g) of each plant powder was used to identify essential substances. The condition of the device was as follows: The gas chromatograph (Agilent6890N) was accompanied by the mass detector Agilent 5973. Column: HP - 5 (30 m long $0.25 \mathrm{~mm}$ (ID) $50.25 \mu \mathrm{m}$ ) fixed phase thickness); Type of injection: Split / gap and column temperature programme: $50{ }^{\circ} \mathrm{C}$, holding time $0.00 \mathrm{~min}$ and rate $-\mathrm{oC} / \mathrm{min}$; temperature $200{ }^{\circ} \mathrm{C}$, holding time 0.00 minutes and rate $5{ }^{\circ} \mathrm{C} / \mathrm{min}$ and temperature $240{ }^{\circ} \mathrm{C}$, holding time 0.00 minutes and rate $10{ }^{\circ} \mathrm{C} / \mathrm{min}$ Carrier gas: helium (99.999\%); Type injection: no gap; Library: Willy $7 \mathrm{n}$; injector temperature: $250^{\circ} \mathrm{C}$ and flow rate: $0.9 \mathrm{ml}$ per minute. chemical compounds. Therefore, in this study, hawthorn fruit extract was extracted by HS-SPME method and by GC-MS method was identified. According to the results, hawthorn fruit has 50 chemical compounds in this essential oil. Essential oils are a complex compound of fat and volatile compounds that are prone to oxidation and degradation. There is only one study on the physicochemical properties of $C$. pontica fruit and that is to measure the phenolic and flavonoid content of $C$. pontica (12) while we have identified and reported every chemical composition of hawthorn fruit essential oil. According to one study, the total phenols, total flavonoid content, and antioxidant activity of $C$. pontica were in the range of 21.19-69.12 mg gallic acid equivalent (GAE)/g dry weight (dw), 2.44-6.08 mg quercetin equivalent (QUE)/g dw and $0.32-1.84 \mathrm{mmol} \mathrm{Fe++/g}$ $\mathrm{dw}$, respectively (12). Hyperoside $(0.87-2.94 \mathrm{mg} / \mathrm{g}$ $\mathrm{dw})$, chlorogenic acid $(0.06-1.16 \mathrm{mg} / \mathrm{g} \mathrm{dw})$, and 
Table 2. Chemical composition of hawthorn fruit

\begin{tabular}{|c|c|c|c|}
\hline No. & Retention time & Compound & $\begin{array}{c}\text { Percentage of compound(s) } \\
\text { (\%) }\end{array}$ \\
\hline 1 & 4.64 & 2-Hexenal & 12.42 \\
\hline 2 & 6.22 & ALPHA-PINENE & 15.40 \\
\hline 3 & 7.24 & Sabinene & 4.33 \\
\hline 4 & 7.61 & beta.-Myrcene & 7.89 \\
\hline 5 & 7.96 & l-Phellandrene & 0.73 \\
\hline 6 & 8.33 & ALPHA. TERPINENE & 0.10 \\
\hline 7 & 8.67 & beta-Thujene & 17.21 \\
\hline 8 & 9.10 & 3-Carene & 0.28 \\
\hline 9 & 9.42 & gamma-Terpinene & 0.17 \\
\hline 10 & 9.76 & cis-sabinene hydrate & 0.24 \\
\hline 11 & 10.21 & ALPHA.-TERPINOLENE & 0.08 \\
\hline 12 & 10.64 & Linalool & 0.13 \\
\hline 13 & 11.36 & Alloocimene & 0.51 \\
\hline 14 & 12.56 & 2-cyclononine-1-ol & 0.11 \\
\hline 15 & 13.27 & alpha.-Terpineol & 0.25 \\
\hline 16 & 14.04 & 1-Hexadecene & 0.32 \\
\hline 17 & 15.17 & 1-Pentadecene & 5.89 \\
\hline 18 & 16.34 & Thymol & 0.07 \\
\hline 19 & 16.44 & 3,4-Diethylphenol & 0.04 \\
\hline 20 & 16.79 & Camphene & 0.19 \\
\hline 21 & 17.06 & Bicycloelemene & 1.34 \\
\hline 22 & 18.12 & Copaene & 2.34 \\
\hline 23 & 18.36 & Beta- Burbonene & 0.23 \\
\hline 24 & 18.46 & beta-Cubebene & 0.19 \\
\hline 25 & 18.54 & Beta-elemene & 0.34 \\
\hline 26 & 18.98 & alpha-Gurjunene & 0.30 \\
\hline 27 & 19.12 & Isoedene & 0.14 \\
\hline 28 & 19.34 & trans-Caryophyllene & 8.76 \\
\hline 29 & 19.51 & Gamma-Cadinene & 0.60 \\
\hline 30 & 19.60 & alpha.-Bergamotene & 1.03 \\
\hline 31 & 19.79 & Zingiberene & 0.17 \\
\hline 32 & 20.15 & trans-beta-Farnesene & 3.50 \\
\hline 33 & 20.38 & Calarene & 0.30 \\
\hline 34 & 20.58 & Epizonzrene & 0.17 \\
\hline 35 & 20.71 & Beta-Himachalene & 0.30 \\
\hline 36 & 20.86 & GERMACRENE-D & 3.44 \\
\hline 37 & 21.10 & Gamma-Cadinene & 0.44 \\
\hline 38 & 21.21 & bicyclogermacrene & 1.88 \\
\hline 39 & 21.43 & beta.-Bisabolene & 0.58 \\
\hline 40 & 21.63 & Alpha Amorphene & 0.65 \\
\hline 41 & 21.84 & delta-Cadinene & 2.67 \\
\hline 42 & 22.22 & CIS-ALPHA-BISABOLENE & 0.60 \\
\hline 43 & 22.59 & sesquisabinene hydrate & 0.12 \\
\hline 44 & 23.28 & Spathulenol & 0.22 \\
\hline 45 & 23.33 & Caryophyllene oxide & 0.23 \\
\hline 46 & 23.45 & Hexadecane & 0.10 \\
\hline 47 & 23.58 & gamma-Gurjunene & 0.09 \\
\hline 48 & 25.09 & Aromadendrene & 0.11 \\
\hline 49 & 25.41 & Valeranone & 0.19 \\
\hline 50 & 30.51 & Bis(2-ethylhexyl) phthalate & 2.61 \\
\hline
\end{tabular}

The recorded chromatogram of the essential oils of the hawthorn fruit oil is shown in Fig. 2. This extract has 50 peaks, corresponding to 50 chemical compounds specified in Table 1. Table 2 also shows the molecular formula and major chemical structure of the main constituents of hawthorn fruit essential oil.

isoquercetin $(0.24-1.59 \mathrm{mg} / \mathrm{g} \mathrm{dw})$ were found to be the most abundant phenolic compounds in the extracts of hawthorn fruits (12).

Essential oils are aromatic oil liquids derived from plant materials such as flowers, seeds, leaves, tree bark, wood, fruit, roots and buds (13). The results of the phytochemical analysis of Crataegus oxyacantha essential oil showed that the plant contains twenty-five compounds, Longifolenaldehyde, $\beta$-Selinene and the main eugenol composition is slightly combined (14). 

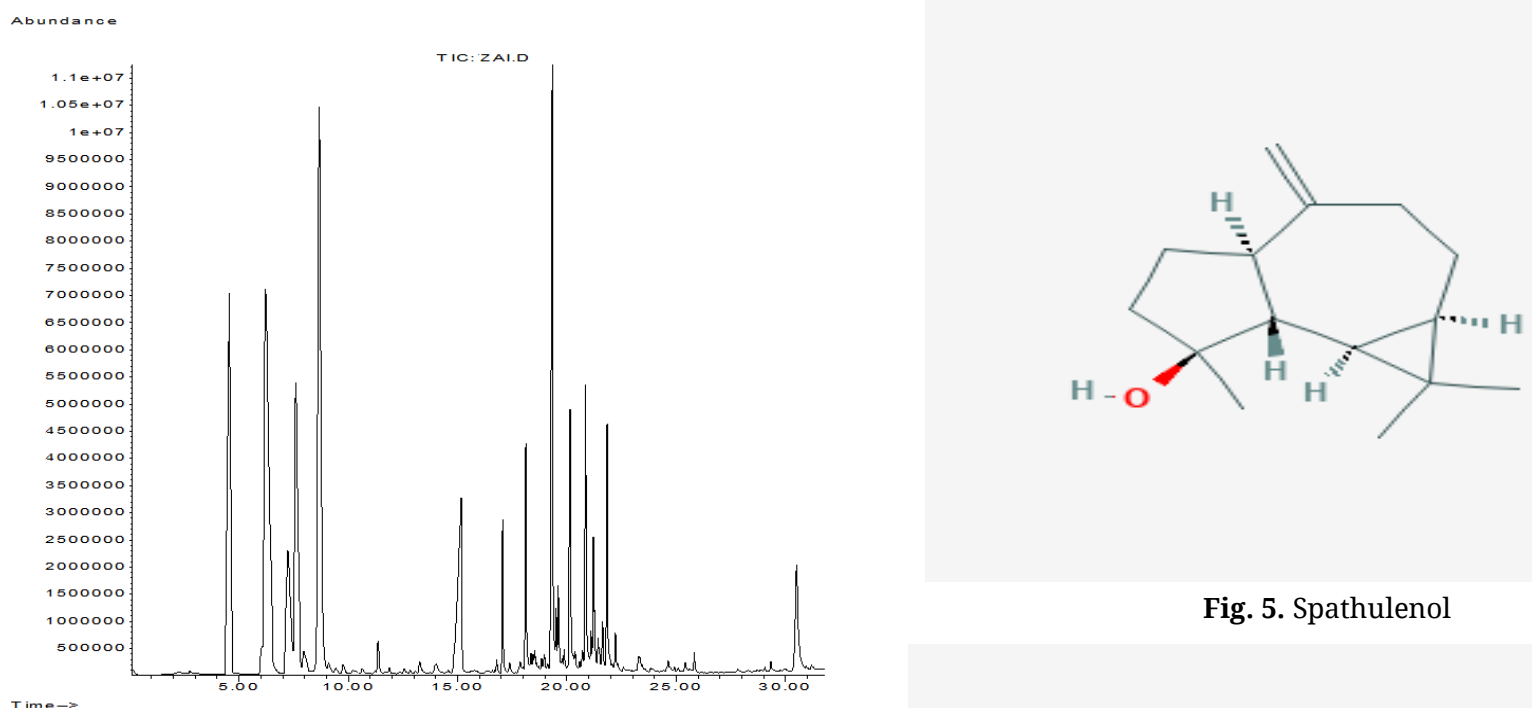

Fig. 2. Chromatogram related to the essential oil of Crataegus pontica fruit.

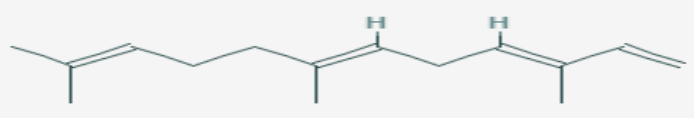

The molecular formula and major chemical structure of the main compounds of Crataegus pontica fruit essential oil are shown in Fig. 3-9.

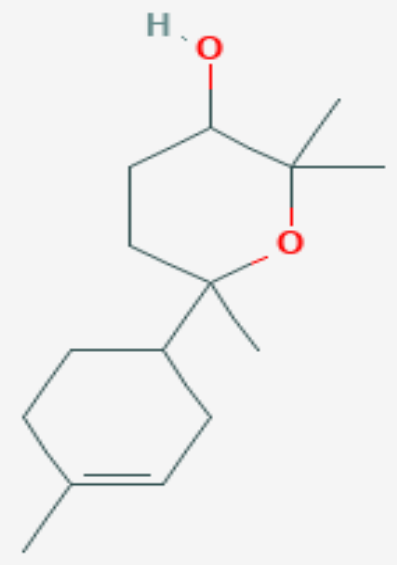

Fig. 6. Farnesene

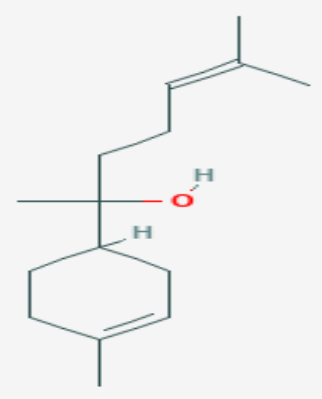

Fig. 7. alpha-Bisabolol

Fig. 3. alpha-Bisabolol oxide A
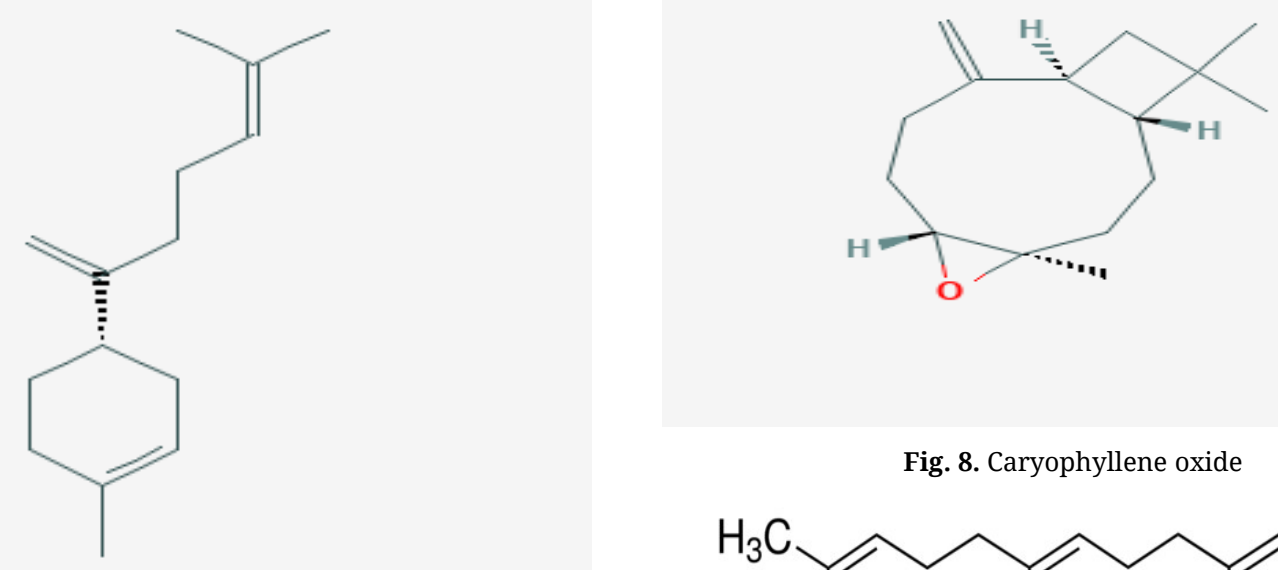

Fig. 4. Beta-Bisabolene

Fig. 8. Caryophyllene oxide

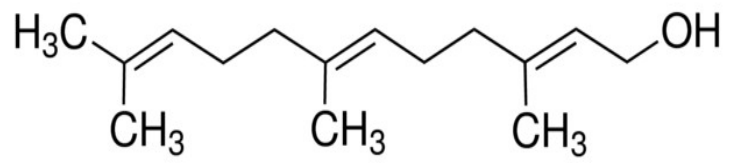

Fig. 9. trans-Farnesole 
The results of a study showed that $C$. pinnatifida extract had compounds of 4 monoterpene glycosides, pinnatifidanosides A-D; phenolic glycoside, pinnatifidanoside E; byzantionoside B, (3S, 5R, 6R, 7E, 9R) -3.6-epoxy-7- megastigmen-5, 9-diol-9-O- $\beta$-D-glcp, $(65,7 \mathrm{Z}, 9 \mathrm{R})$ - roseoside , icariside $\mathrm{B} 6$, linalool oxide $\beta$ D-glc, shanyenoside A, dihydrocharcone-2'- $\beta$-D-glc, eriodectyol, vitexin, 2 " -O-rhamnosyl vitexin (15). The results of a study shown that $C$. pinnatifida extract had Norhawthornoids A, B compounds; sesquiterpenoids shnyegenin $B$, shnyeside $B,(3 S, 5 R$, 6R, 7E, 9S) - megastiman-7-ene-3,5,6,9-tetrol, euodionosides D, (6R, 9R) -3-oxo- $\alpha$ - ionol-9-O- $\beta$-Dglucopyranoside, (6S, 7E, 9R) -6,9-dihydroxy-4,7megastiymadien-3-one-9-O- [ $\beta$-D-xylopyranosy- $\beta$-D glucopyranoside], linarionosides A, B, C; 3,9dihydroxy-5-megastigmen-3-O- [ $\beta$-D-xylopyranosy- $\beta$ Dglucopyranoside], pinnatifidanosides C, F, G. (16). The results of a study showed that $C$. azarolus var. aronia contains azarolic acid compounds, 4 known phenolic compounds; 4 is known as triterpene acids (17).

The results of a study showed that $C$. monogyna extract had 3 hydroxycinnamic and 1 hydroxybenzoic acid compounds, 6 glucosylated flavonols and 2 flavones, 2 cyanidin glycosides; (picatechin, a dimer B2, two trimers, C1 and C2) (18). The results of a study revealed that $C$. pycnoloba extract had a composition of 4 dibenzofurans discovered compound 6-hydroxy-2,3,4trimethoxydibenzofuran; ursolic aldehyde (19). As can be seen from different studies, different species of hawthorn have different compounds. In this study, C. pontica essential oil was studied for the first time, and the most important composition of $C$. pontica fruit essential oil included beta-Thujene. BetaThujene is a natural organic compound of the monoterpene class that is found in the essential oils of a variety of plants and helps to flavour some plants. Thujene has antibacterial and antifungal properties and can be used for antimicrobial purposes. Studies have shown that medicinal plants and natural products have beneficial effects on human health due to the active ingredients and their medicinal and antioxidant compounds and have a therapeutic effect on various organs and various disorders and diseases of the body (20-29).

\section{Conclusion}

In general, it can be said that the essential oil of this plant is influenced by various environmental and intrinsic factors both in quantity and in its constituents the main compound being beta-Thujene, alpha-pinene, 2-Hexenal and trans-Caryophyllene and the highest concentration of this compound among them. These compounds can be used as antioxidant compounds after further testing, so identifying the active ingredients of each herb is a useful way to produce effective drugs. In the future.

\section{Acknowledgements}

Authors would like to thank the Vice-chancellor for the Research and Technology Deputy of the Ilam
University of Medical Sciences and Biotechnology and Medicinal Plants Research Center for funding this study.

\section{Authors' contributions}

NB, AGH and MT reviewed the literature and prepared the first draft of manuscript; PSH helped in preparing first draft of manuscript, verified and corrected. All authors read and approved the final report.

\section{Conflict of interests}

All authors declare that no conflict of interest exists.

\section{References}

1. Mozaffarian VA. Flora of Ilam Province. Contemporary Culture Publication, Tehran, 2008; pp.567.

2. Ahumada C, Saenz T, Garcia D, De La Puerta R, Fernandez A, Martinez E. The effects of a triterpene fraction isolated from Crataegus monogyna Jacq. On different acute inflammation models in rats and mice. Leucocyte migration and phospholipase A2 inhibition. J Pharm Pharmacol. 1997;9 (3):329-31. https://doi.org/10.1111/j.2042-7158.1997.tb06806.x.

3. Schwinger RH, Pietsch M, Frank K, Brixius K. Crataegus special extract WS 1442 increases force of contraction in human myocardium cAMP independently. J Cardiovasc. Pharma. 2000; 35(5):700-77. https://doi.org/10.1097/00005344-200005000-00004

4. Lee YA, Kim YJ, Cho EJ, Yokosuka T. Ameliorative effects of proanthocyanidin on oxidative stress and inflammation in streptozotocininduced diabetic rats. J Agricult Food Chemistry. 2007;55 (23):9395- 400. https://doi.org/10.1021/jf071523u

5. Dolatkhani P, Jamei R. Antioxidant properties and medicinal uses of some Crataegus spp. (Hawthorn) including $C$. meyer and $C$. pontica. Current Nutr Food Sci. 2015;11(2):116-23.

6. Elliott Middleton Jr, Kandaswami $\mathrm{CH}$, Theoharides TC. The Effects of Plant Flavonoids on Mammalian Cells: Implications for Inflammation, Heart Disease, and Cancer. Pharmacolog Rev. 2000;52 (4):673-751.

7. Svedstrom U, Vuorela H, Kostiainen R, Tuominen J, Kokkonen J, Rauha JP, Laakso I, Hiltunen R. Isolation and identification of oligomeric procyanidins form Crataegus leaves and flowers. Phytochem. 2002;60(8):821-25. https://doi.org/ 10.1016/s00319422(02)00172-3

8. Harborne J, Williams A. Advances in flavonoid research since. Phytochem. 2000;55(6):481-504. https://doi.org/10.1016/s00319422(00)00235-1

9. Milddleton E, Kandaswami CH, Theoharides TC. The effects of plant flavonoids on mammalian cells: implications for inflammation, heart disease, and cancer. Pharmacol Rev. 2000;52(4):673-751.

10. Lord H, Pawliszyn J. Evolution of solid-phase microextraction technology. J Chromatography A. 2000;885 (1-2):153-93.

11. Bahmani M, Taherikalani M, Khaksarian M, Soroush S, Ashrafi B, Heydari R. Phytochemical profiles and antibacterial activities of hydroalcoholic extracts of Origanum vulgare and Hypericum perforatum and Carvacrol and Hypericin as a Promising Anti-Staphylococcus aureus. Mini Rev Med Chem. 2019;19(11):923-32.

$10.2174 / 1389557519666190121124317$ https://doi.org/

12. Alirezalu A, Ahmadi N, Salehi P, Sonboli A, Alirezalu K, Mousavi Khaneghan A et al. Physicochemical characterization, antioxidant activity, and phenolic compounds of hawthorn (Crataegus spp.) fruits species for potential use in food applications. Foods. https://doi.org/10.3390/foods9040436 
13. Asbahani AEI, Addi EH, Bitar A, Casabianca H, Elaissari A Hartmann DJ, et al. Preparation of medical cotton textile activated by Thymus leptobotrys essential oil colloidal particles: Evaluation of antifungal properties. J Colloid Sci Biotechnol. 2014;3(3):253-61.

14. Chouitahand O, Meddah B. Essential Oil from the Leaves of Crataegus oxyacantha: Chemical composition and antimicrobial activity. Biolog Forum. 2018;10(1):52-55.

15. $\mathrm{Li} \mathrm{WQ}, \mathrm{Hu} \mathrm{QP}, \mathrm{Xu}$ JG. Changes in physicochemical characteristics and free amino acids of hawthorn (Crataegus pinnatifida) fruits during maturation. Food Chem. 2015;175: 50-56. https://doi.org/10.1016/j. foodchem.2014.11.125.

16. Guo R, Lin B, Shang XY, Zhou L, Yao GD, Huang XX, et al Phenylpropanoids from the fruit of Crataegus pinnatifida exhibit cytotoxicity on hepatic carcinoma cells through apoptosis induction. Fitotera. 2018;127:301-07. https://doi.org/10.1016/j.fitote.2018.03.003.

17. Mahmud SA, Al-Habib OAM, Bugoni S, Clericuzio M, Vidari G. A new ursane-type triterpenoid and other constituents from the leaves of Crataegus azarolus var. aronia. Nat Prod Commun. 2016;11(11):1637-39.

18. Mraihi F, Hidalgo M, de Pascual-Teresa S, Trabelsi-Ayadi M, Cherif JK. Wild grown red and yellow hawthorn fruits from Tunisia as source of antioxidants. Arab J Chem. 2015;8(4):570 78. https://doi.org/10.1016/j.arabjc.2014.11.045.

19. Agalou A, Thrapsianiotis M, Angelis A, Papakyriakou A, Skaltsounis $\mathrm{AL}$, Aligiannis $\mathrm{N}$, et al. Identification of novel melanin synthesis inhibitors from Crataegus pycnoloba using an in-vivo Zebrafish phenotypic assay. Front Pharmacol. 2018;9:265. https://doi.org/10.3389/ fphar.2018.00265.

20. Moayeri A, Azimi M, Karimi E, Aidy A, Abbasi N. Attenuation of morphine withdrawal syndrome by Prosopis farcta extract and its bioactive component luteolin in comparison with clonidine in rats. Med Sci Monit Basic Res. 2018;24(9):151-158. https://doi.org/10.12659/MSMBR.909930

21. Bahmani M, Taherikalani M, Khaksarian M, Rafieian-Kopaei M, Ashrafi B, Nazer M, et al. The synergistic effect of hydroalcoholic extracts of Origanum vulgare, Hypericum perforatum and their active components carvacrol and hypericin against Staphylococcus aureus. Future Sci OA 2019; 5(3):FSO371.

22. Abbasi N, Khosravi A, Aidy A, Shafiei M. Biphasic response to luteolin in MG-63 osteoblast-like cells under high glucoseinduced oxidative stress. Iran J Med Sci. 2016;41(2):118-25.

23. Zangeneh MM, Ghaneialvar H, Akbaribazm M, Ghanimatdan M, Abbasi N, Goorani S, et al. Novel synthesis of Falcaria vulgaris leaf extract conjugated copper nanoparticles with potent cytotoxicity, antioxidant, antifungal, antibacterial and cutaneous wound healing activities under in-vitro and in-vivo condition. J Photochem Photobiol B: Biol. 2019;197: 111556 https://doi.org/10.4155/fsoa-2018-0096

24. Mahdavi B, Saneei S, Qorbani M, Zhaleh M, Zangeneh A Zangeneh MM, et al. Ziziphora clinopodioides Lam. leaves aqueous extract mediated synthesis of zinc nanoparticles and their antibacterial, antifungal, cytotoxicity, antioxidant and cutaneous wound healing properties under in-vitro and invivo conditions. Appl Organom Chem. 2019;33 (11):e5164.

25. Valadi A, Nasri S, Abbasi N, Amin GR. Antinociceptive and antiinflammatory effects of hydroalchoholic extract of Anethum graveolens L. seed. J Med Plants. 2010;9(34):124-30.

26. Karami N, Karimi M, Bahmani M. Constipation: An ethnobotanical study of medicinal plants used for constipation in Shahrekord city, Chaharmahal \& Bakhtiari province, Iran Plant Biotechnol Persa. 2020;2(1):1-7.

27. Gholami-Ahangaran M, Ahmadi-Dastgerdi A, Karimi-Dehkordi M. Thymol and carvacrol; as antibiotic alternative in green healthy poultry production. Plant Biotechnol Persa 2020;2(1):22-25.

28. Alizadeh M. Safarzadeh A, Bahmani M, Beyranvand F, Mohammadi M, Azarbaijani K, et al. Brucellosis: Pathophysiology and new promising treatments with medicinal plants and natural antioxidants. Asian Pacific J Trop Med. 2018;11(11):597-608.

29. Magbool FF, Elnima EI, Shayoub ME, Hamedelniel EI, Gamil AM, E. Adam ME et al. Formulation, design, development and evaluation of Quercus infectoria galls extract oral gels. Plant Biotechnol Persa. 2020;2 (2):1-13. 